\title{
OS LIMITES DA REPRESENTAÇÃO E DO POLÍTICO: um diálogo entre os debates da judicialização da política no Brasil e o pensamento de Carl Schmitt
}

\author{
Isabele Sales dos Anjos \\ Universidade do Estado do Rio de Janeiro (UERJ) \\ E-mail: isa.isabeleanjos@gmail.com
}

\begin{abstract}
RESUMO
Os debates acerca da relação entre a esfera política e a jurídica tem ocupado grande parte da agenda de pesquisa nos campos das Ciências Sociais e do Direito. Isto se deve às proporções em que as dinâmicas imbricadas nesta relação alcançaram no modus operandi dos processos democráticos dos Estados modernos de direito, que ficaram conhecidas e popularizadas pelo fenômeno denominado "Judicialização da Política". No Brasil a discussão ganhou destaque nas décadas subsequentes ao estabelecimento da Constituição de 1988, quando as decisões do trabalho do Judiciário ao interpretar a Constituição passam a exercer um papel central no processo de democratização. Este trabalho visa apresentar um diálogo entre os debates sobre judicialização da política produzidos no Brasil e as contribuições teóricas de Carl Schmitt presentes em sua crítica ao liberalismo.
\end{abstract}

Palavras-chave: Judicial da política, Carl Schmitt, Conceito do político.

\section{THE LIMITS OF REPRESENTATION AND OF POLITIC: a dialog between the debats of judicial of politic in Brazil and the thinking of Carl Schmitt}

\begin{abstract}
The debates about the relationship between the political and legal sphere has occupied a large part of the research agenda in the fields of social sciences and law. This is due to the interwoven dynamic proportions in this respect reached in the modus operandi of the democratic processes of the modern States of law, which became known and popularized by the phenomenon called "Judicialization of politics". In Brazil, the discussion came to prominence in the decades since the establishment of the Constitution of 1988, when the decisions of the Judiciary when interpreting the Constitution shall have a central role in the process of democratization. This work aims to present a dialogue between the debates over judicialization of politics produced in Brazil and theoretical contributions of Carl Schmitt present in your critique of liberalism.
\end{abstract}

Keywords: Judicial of politics; Carl Schmitt; Concept of politic. 


\section{INTRODUÇÃO}

A judicialização da política é um fenômeno que tem tomado, cada vez mais, a centralidade nas discussões em torno do papel do Estado democrático de direito na medida em que as decisões pertinentes à esfera política são tomadas por meio da intervenção e atuação do poder judiciário. No Brasil este fenômeno ganhou destaque, tanto nas agendas de pesquisa das ciências sociais e do direito, quanto na opinião pública, ao passo que a Carta Constitucional de 1988 permitiu uma maior atuação do poder judiciário, a fim de expandir os canais de participação democrática. Contudo, ao decidir sobre questões que afetam até mesmo a engenharia política estatal, as ações do poder judiciário foram alvo de inúmeras críticas, dentre elas as que afirmam que o judiciário excede suas obrigações interferindo no funcionamento dos poderes legitimamente representativos. Nesse sentido, o debate sobre elementos fundamentais à própria composição da engenharia política do Estado se faz pertinente, a saber: soberania, legitimidade, autoridade, decisão e, até mesmo, o político.

Todavia, a proposta deste trabalho não é o de realizar um debate sobre cada um desses elementos de maneira diacrônica, e tão pouco revisá-los cotejando as extensas e distintas discussões que incidem diretamente sobre a temática da judicialização da política. A tarefa que me disponho a realizar é a de apresentar alguns pontos de diálogo entre as contribuições do pensamento de Carl Schmitt, no que tange a crítica que realiza sobre o liberalismo, na qual esses elementos se manifestam, e os debates sobre judicialização da política produzidos no Brasil. No entanto, o leitor não encontrará aqui um levantamento exaustivo de toda a produção discursiva acerca da temática da judicialização da política no Brasil, nem a correlação com uma extensa análise da obra de Schmitt, mas o esforço de apresentar um exercício analítico, ainda incipiente, entre os pressupostos que considero fundamentais à ambas as partes que intento discorrer neste trabalho, na tentativa de pensar Carl Schmitt e a judicialização no Brasil sob o ponto de vista do político (ainda que isto possa parecer, num primeiro momento, trivial).

O artigo está organizado em três partes, a saber: “O estado da arte: a Judicialização da Política e algumas considerações sobre a temática no Brasil”, no qual realizo uma apresentação geral do tema da judicialização da política e alguns apontamentos sobre os debates desta temática no Brasil; "Carl Schmitt: o conflito, o político, a soberania, a decisão e o Estado de Direito”, em que exponho, a partir do conceito do político, a estrutura da crítica que Schmitt realiza ao Estado liberal; e "Entre o poder jurídico e o poder político: representação, decisão e soberania no Estado democrático de Direito pós 1988 no Brasil", nesta parte, busco, a partir das questões levantadas em torno do conceito do político, em que pesa a crítica de Carl Schmitt ao liberalismo, realizar um exercício que envolve, para além de uma mera correlação, pensar a judicialização e o papel do 
judiciário, em particular no Brasil, sob a concepção do conflito eminente, da polêmica que organiza a esfera do político.

\section{O ESTADO DA ARTE: A JUDICIALIZAÇÃO DA POLÍTICA E ALGUMAS CONSIDERAÇÕES SOBRE A TEMÁTICA NO BRASIL}

Desde a publicação do livro The Global Expansion of Judical Power de C. Neal Tate e Torbjörn Vallinder, em 1995, o termo “judicialização da política” vem sendo amplamente adotado para apreender as dinâmicas das relações entre o poder judiciário e os processos políticos inerentes à vida em sociedade e à engenharia política estatal nas democracias constitucionalistas modernas; tanto para os casos em que o judiciário é requisitado a intervir e decidir sobre determinada disputa política, quanto para aqueles em que o judiciário assume a postura de participante ativo (MACIEL; KOERNER, 2002; RODRIGUES, 2016).

A tentativa de dar ao termo "judicialização da política" um status de conceito analítico, tal como Rodrigues (2016) e Maciel \& Koerner (2002) apontam, não foi levado adiante pelos seus precursores, ainda que tenham introduzido de maneira irreversível a expressão ao vocabulário e a agenda de estudos das ciências sociais e do direito. A judicialização da política, nesse sentido, passou a ser acionada sob estruturas analíticas diferentes, abrangendo outros aspectos e ganhando espaços em outras arenas de disputa; desde as intervenções no campo de elaboração de políticas públicas e os contínuos movimentos de incorporação do vocabulário e da estrutura do direito na esfera política e nas relações sociais, passando pela função daquele que decide sobre as matérias das agendas dos poderes executivo e legislativo, até mudanças efetivas na estrutura social e estatal transformações no regime político, processos de construção de nações, formação de identidades coletivas e planejamento macroeconômico ou de segurança nacional, por exemplo.

Hirschl (2009) ${ }^{1}$, ao apresentar uma nova face do fenômeno da judicialização, nos indica que quando as intervenções do poder judiciário na esfera política passam a impactar na organização social e estatal, a ponto de redefinir as suas próprias bases, cabe observar as dimensões dos eventos para além da relevância política das questões tratadas. Compreendendo, nesse sentido, que o mérito da distinção sobre o que deve ser subsumido pelas diferentes categorizações dos casos de intervenção do poder judiciário esteja inscrito mais num conjunto de valores que orientam o que é compreendido por política, "esfera do político"2 e decisão "política", do que em um composto de pré-requisitos que um ou outro caso deva cumprir para que seja discriminada sua natureza junto a um conjunto fatos.

Assim, ao tomar os casos que perfazem o fenômeno da judicialização da política a partir desta perspectiva, demanda-se que as questões de ordem ontológica acerca das principais dimensões 
que os compõem sejam exploradas e debatidas a fim de ampliar o quadro de referências no qual são operacionalizadas e apreender os seus limites ${ }^{3}$. Neste trabalho pretendo traçar um diálogo com duas dimensões que acredito ser fundamentais ao escopo do campo de investigação do fenômeno da judicialização, cotejando o caso brasileiro e as contribuições teóricas presentes no pensamento de Carl Schmitt, a saber: a representação e o político.

No Brasil, as discussões em torno da judicialização da política são construídas, a meu ver, de acordo com algumas concepções sobre um modelo democrático em que ampliam-se o grau de liberdade de contestação pública e de participação ${ }^{4}$, e um republicanismo em um formato federado que, sob novos arranjos constitucionais, intentava prolongar um cenário em que os seus cidadãos tivessem garantidos os seus direitos individuais, coletivos e políticos, e as instituições permanecessem protegidas da discricionariedade e da contingência. O momento pós-1988 permitiu a ampliação do campo de atuação de diferentes organizações e instituições de variadas áreas localizadas nos três níveis da engenharia política estatal - o federal, o estadual e o municipal. Os tribunais também assumiram um maior protagonismo nessa conjuntura, bem como os seus operadores, na medida em que se tornam um canal de ampliação de participação e de contestação pública.

Nesse sentido, o termo judicialização da política passou a ser utilizado, já nos anos 1990, em pesquisas empíricas de autores como Castro (1996), em análises como as de Werneck Vianna ${ }^{5}$ sobre as Ações Diretas de Inconstitucionalidade (ADIs) que mobilizavam o STF nas decisões políticas de atores localizados nas esferas do poder executivo e, principalmente, do poder legislativo, e em estudos como os de Rogério Arantes sobre os efeitos do ativismo do poder judicial e de instituições como o Ministério Público nas funções políticas de instituições representativas. Contudo, a judicialização não demorou muito para obter, também, destaque nos debates públicos. A expressão passou a compor o quadro de referência dos atores políticos, dos operadores do direito, da opinião pública e, principalmente, dos veículos de comunicação; a mídia latu senso (MACIEL; KOERNER, 2002).

Nesse movimento, a expressão judicialização da política foi popularizada, ganhando múltiplas interpretações e significados que por vezes se contradiziam, mas não inibiram seus usos, e, tão pouco, deixou-os com menor intensidade na esfera política e nas relações sociais e pessoais. A disseminação do termo na esfera pública fez com que as opiniões acerca da centralidade das decisões do trabalho do poder judiciário, ao interpretar a Constituição no contínuo do processo democrático brasileiro, gerassem duas compreensões: 1) as atividades e decisões do poder judiciário são necessárias ao desenvolvimento democrático, preservando a Constituição dos atos discricionários dos poderes políticos representativos; 2) as atividades e decisões do poder judiciário 
usurpam as funções do soberano, o povo, legitimamente representado, impactando de maneira negativa no funcionamento das instituições, de fato, representativas.

Ambos os pontos de vista contribuem para a reabertura, tal como mencionado, do debate acerca da representação, que, a meu ver, parece muita das vezes tratar de uma questão normativa dos requisitos que alguns intérpretes da democracia acreditam ser imprescindíveis à longevidade deste sistema. Nele o poder judiciário aparece ou como uma instituição que contribui para a preservação da idoneidade do exercício da representação, evitando que os representantes desvirtuem de suas obrigações por motivações que não atendem ao interesse público, ou como um poder que exacerba os seus limites de atuação, reduzindo a capacidade das ações das outras esferas de poder que são concebidas como legitimas à representação, em que pese que essas esferas legitimas de representação já respondem a exigências que as conduzem ao exercício da sua função, visando atender as demandas de seus representados (PRZEWORSKI, 1997). Contudo, é sabido que a representação está inserida num campo em que, ainda que pareça imperceptível àqueles que estão imersos nele, o conflito dita o código de conduta e determina quais os interesses que serão atendidos por aqueles que foram escolhidos para a função de representante.

Assim, ao que me parece, o poder judiciário e suas incursões vão no sentido desse conflito, próprio do campo democrático, e tentam operacionalizá-lo para uma determinada direção. Logo, o debate sobre o político se faz presente e essencial para repensar elementos que estão imbricados no contexto brasileiro pós-1988, a saber: soberania, legitimidade, autoridade e decisão. Estes elementos, tal como argumentarei adiante, estabelecem os próprios limites da representação e do político.

\section{CARL SCHMitT: O CONFLito, o POLÍtico, A SOBERANiA, A DeCisão E O ESTADO DE DIREITO}

Carl Schmitt é considerado um dos maiores pensadores da teoria política contemporânea. O autor possui uma vasta obra construída ao longo de mais de seis décadas de atividade intelectual. Schmitt, muito lembrado por ter se associado com o regime nazista do Terceiro Reich alemão, foi por muito tempo relegado ao roll dos autores malditos. No entanto, ainda que seja inegável que a adesão de Carl Schmitt ao nazismo não se trata de um mero acidente de percurso e que isso resulta, para muitos, na relação indissociável entre o exercício de suas funções durante os anos em que foi colaborador deste regime e a sua produção intelectual, não significa afirmar que sua filiação consistiu numa necessidade substantiva para a sua reflexão teórica, ou que a sua decisão e os desdobramentos dela esgotem todo o sentido de sua obra. 
Carl Schmitt foi de longe um dos maiores críticos do Estado liberal. Suas críticas, desenvolvidas com base na organização do constitucionalismo alemão, circunscritas e estabelecidas na Constituição de Weimar, se organizam em torno da questão da despolitização da vida pública, que chegou ao clímax durante a república de Weimar, um dos principais problemas em que pesou sua análise. Para Schmitt, o liberalismo, que teve maior expressividade no período em que vigorou a Constituição de Weimar, é um sistema no qual o político encontra-se aleijado, uma vez que, voltado para a preservação da liberdade individual, a dimensão pública da vida social e das funções do Estado encontram-se em um estado de dormência; ou seja, a vida política é relegada à neutralidade e ao apaziguamento das relações. Assim, o Estado liberal para Schmitt havia deixado de lado um dos principais elementos fundantes da vida social, e de si mesmo, o político; a capacidade de distinção do inimigo, próprio do embate que organiza essa esfera.

O político é capaz de abranger em sua estrutura toda sorte de questões e elementos da vida em sociedade, inclusive o próprio Estado. Ele possui autonomia em relação a qualquer outra dimensão, seja social, econômica ou do direito; tal como possuí sobre qualquer instituição produzida por elas. Para Schmitt (2008), a propriedade que permite ao político assumir esta posição em relação às diferentes dimensões da vida social está inscrita, justamente, na sua natureza de conflito eminente; a qual se exprime na díade amigo e inimigo.

Um mundo no qual a possibilidade de semelhante combate estivesse completamente eliminada e desaparecida, um planeta definitivamente pacificado, seria um mundo sem distinção entre amigo e inimigo, por conseguinte, um mundo sem política. (SCHMITT, 2008, p. 37)

O antagonismo amigo e inimigo e as motivações do conflito político devem ser lidas em termos de natureza pública, uma vez que é das mais diversas esferas da vida humana (econômica, religiosa, étnico, cultural, moral etc.) que o político pode extrair sua força. O político se manifesta pelo caso crítico. Se as forças antagônicas, culturais ou religiosas forem tão fortes a ponto de definirem, por si mesmas, a decisão sobre o caso crítico, elas terão se convertido na nova substância da unidade política. (SCHMITT, 2008, p. 41). Portanto, o político não possuí substância própria, ele se exprime a partir de uma relação circunscrita no espaço do conflito.

O político, que tem por condição o conflito eminente, passa a ser comprimido no arranjo liberal constitucionalista do Estado de direito e a ter suas propriedades limitadas em âmbito estatal. Pois, uma vez que as funções estatais estão relegadas à garantia irrestrita das liberdades individuais, o espaço do político tende a desaparecer. Contudo, mesmo sofrendo esse tipo de processo, o político é o elemento fundante de uma comunidade política e do corpo do Estado, e estes só podem ser compreendidos no sentido polêmico do conflito político, naturalmente. O político ordena e dá sentido ao que se compreende por povo, seu status, o Estado e seu ordenamento jurídico. O Estado 
liberal, ao buscar a eliminação do embate através da pacificação das relações, implica a afirmação de uma esfera ilimitada da liberdade individual como algo anterior ao Estado (FERREIRA, 2004, p. 131), logo, a justificação que o Estado encontra para a sua própria existência estaria no fato de estar a serviço da proteção das liberdades individuais. Entretanto, o político ainda permanece.

Ao pôr em evidência o Art. 48 da Constituição de Weimar que permite ao Presidente do Terceiro Reich lançar mão das medidas que julgar necessárias, com o auxílio da força militar, para o restabelecimento da ordem e da segurança pública nos casos em que estas estejam ameaçadas ou perturbadas, Carl Schmitt abre uma outra seara da crítica que infligi sobre o Estado de direito liberal. Schmitt aponta para a discussão da soberania e da decisão. Cabendo ao Estado, única e exclusivamente, a garantia das liberdades do indivíduo, sendo está função a própria razão de sua existência, este mecanismo constitucional concede poderes irrestritos e discricionários ao soberano para determinar sobre o estado de normalidade no qual desempenhara as funções cabidas à garantia das liberdades dos indivíduos. Para Carl Schmitt, isso implica na afirmação de que o poder soberano é afirmado e tem suas ações legitimadas na medida em que exerce o controle tanto do elemento exógeno (contingência e o conflito político), quanto do endógeno (instituições e instâncias diretas de poder) em prol da sua função fim: a proteção das liberdades do indivíduo.

Este tipo de condição é reflexo da maneira como, no constitucionalismo liberal, a lei e o direito estabelecem uma relação harmônica na qual não há a sensação do exercício da dominação do poder de alguns homens sobre os demais, mas sim a crença de que há o predomínio das leis e que o legislador, e todo o procedimento aplicado por este, é o último guardião de todo o Direito; da garantia da ordem existente, da segurança e da proteção contra tudo aquilo que está circunscrito fora da esfera da legalidade (FERREIRA, 2004). A dominação das leis no Estado de direito liberal e a confiança no legislador e no procedimento constituem toda a base da legalidade do Estado. Para Carl Schmitt, este modus operandi do Estado de direito liberal é o que garante a unidade política, uma vez que é o Presidente do Reich a personificação do próprio constitucionalismo ${ }^{6}$. Isto, ao meu ver, permitiria, também, a exposição dos indivíduos, os quais o Estado deveria proteger, aos abusos do poder daquele que exerce a soberania e de uma maioria não substantiva, tal como ocorreu no regime nazista, amparado pelo Art. 48 da Constituição de Weimar, que prolongou a sua vigência. Revelando também o regime da exceção como uma maneira de impor a ordem. Com isso, a crise da ordem política alemã se incorpora à análise de Schmitt como uma experiência de exceção concreta, em face da qual as debilidades do liberalismo se revelam em toda a sua extensão. (Ferreira 2004:140).

Tomando como eixo central da organização do pensamento de Carl Schmitt a própria polêmica em torno do político e de sua relação com o Estado de direito liberal, é possível apreender, 
talvez afirmar, que este último exerce controle sobre o político (lido como o conflito, a contingência) fazendo uso irrestrito do poder político sob a anuência do sistema de direito. Nesse sentido, esvazia-se o político em seu caráter público e dá-se espaço à exceção, que reintroduz o caráter limite (conflito eminente) do político no interior do aparente cenário de pacificação do Estado de direito. Dessa maneira, o poder de decisão exercido pelo controle do conflito político, ao ser chancelado pelo procedimento do constitucionalismo liberal, dá aquele que exerce o poder político a autoridade de definir em que momento acaba e termina o conflito; para além, é claro, de determinar quem ou aquilo que está circunscrito fora da esfera da legalidade, que possa representar algum risco a ordem e a segurança pública estabelecida em prol da proteção da liberdade do indivíduo - tendo em vista que é o Presidente do Reich que, segundo Carl Schmitt, representaria a própria unidade política.

Nesse sentido, posso afirmar com certa segurança, que para Carl Schmitt é o Chefe de Estado (o Presidente do Reich) que tem a autoridade e legitimidade para realizar o controle da constitucionalidade dentro da comunidade política, uma vez que ele representa o próprio poder de integração política. Isto é subscrito pelo próprio sistema de direito, dada a presença do Art. 48. Logo, Schmitt afasta a possibilidade de que um Tribunal Constitucional tome frente às decisões sobre questões políticas e constitucionais. Tomando, tal como discorri, o político como uma esfera autônoma que se define no conflito e o sistema de direito e a soberania como conceitos-limite em si mesmo, a decisão sobre o que se estabelece na malha da constitucionalidade é a mesma que os dá substância, logo, antecede a norma, castrando qualquer possibilidade dos tribunais decidirem sobre o político, já que necessitam da combinação da norma e do fato para julgarem; para além, claro, do próprio Schmitt reconhecer a Constitucionalidade como algo que está para além de lei escritas (não circunscritas mediante os fatos), nos quais os fatos são passíveis à alguma espécie de checagem somente a posteriori. A partir da discussão tecida até aqui é possível traçar alguns pontos de diálogo entre os debates acerca da judicialização da política no Brasil e as contribuições de Carl Schmitt. Cabe ressaltar que não intento discorrer por todos os caminhos que tal tarefa possibilita enveredar, procuro, a partir dos pressupostos que considero fundamentais a ambas as partes, organizar algumas digressões que permitam olhar para o fenômeno da judicialização da política, em particular no Brasil, como parte de um processo de transição/estabelecimento de um modus operandi das democracias do século XXI. 


\section{ENTRE O PODER JURÍDICO E O PODER POLÍTICO: REPRESENTAÇÃO, DECISÃO E SOBERANIA NO ESTADO DEMOCRÁTICO DE DIREITO PÓS 1988 NO BRASIL}

Tal como apresentei no tópico de abertura deste texto, no qual expus brevemente o tema da judicialização da política e algumas considerações sobre este debate no Brasil, as causas e efeitos das intervenções do poder judiciário nos processos de decisão política de instituições representativas, na elaboração de políticas públicas e, até mesmo, em mudanças efetivas na estrutura social e estatal, e das incorporações constantes da gramática judicial nas relações sociais, formam a base de provocações através das quais pautaram-se inúmeras investigações sobre o fenômeno da judicialização. No Brasil, particularmente, em meados da década de 1980, momento em que o país caminhava na direção de um modelo democrático no qual o papel da Carta Constitucional foi ímpar para a expansão do exercício da cidadania, a preocupação em consolidar o Estado de direto foi decisivo para conceder aos tribunais atribuições que permitissem ao cidadão a contestação pública e o reclame de acesso aos direitos, tal como acabou por viabilizar esse tipo de ação aos operadores da engenharia política estatal.

Nesse sentido, as discussões sobre a crescente participação do poder judiciário aumentaram na medida em que as decisões deste ao interpretar a Carta Constitucional de 1988 passam a tomar centralidade no processo de desenvolvimento democrático. Autores como Gisele Cittadino ${ }^{7}$ e Thamy Pogrebinschi (2012) apontam que este fenômeno em nada prejudicou o progresso democrático, e, ao contrário do que outros atores e autores envolvidos neste debate afirmam, somente contribuiu para a optimização das relações de representação e avanço da democracia. Cabe salientar que autores como Rogério Arantes, tal como comentado anteriormente, apresentam este tipo de incursão do judiciário (incluso o de outras instituições que são levadas à frente por magistrados, como no caso do Ministério Público) como prejudicial ao funcionamento de instituições representativas (MACIEL; KROENER, 2002). O debate em torno da judicialização da política, é sabido, não se encerra no campo acadêmico, ele também está presente entre juristas e operadores do direito. Recentemente em um Seminário na Escola do Legislativo do Estado do Rio de Janeiro (ligada à ALERJ), foi mencionado, com profunda preocupação por parte de procuradores do legislativos e desembargadores do TJ-RJ, que as tentativas e a permissibilidade que outras esferas do poder judiciário (o STF e o Ministério Público) tem em interferir na condução das atividades legislativas e nos processos políticos decisórios, deixando claro que ao atuar desta maneira o judiciário estaria atrofiando o processo de legislativo (até mesmo em sua fase embrionária), tem gerado problemas na própria representação (ainda que alguns se posicionem a favor do exercício contra majoritário quando enxergam que o legislativo em sua composição não é representativo $)^{8}$ 
O pós-1988, sem sombra de dúvida, dividiu opiniões e análises sobre as causas e os efeitos do trabalho de decisão do poder judiciário como intérprete da Constituição. Essa expansão da atuação do poder judicial frente a estas visões tão divergentes (que ainda repercutem nas discussões e nas análises políticas atualmente) acerca do seu papel no processo de desenvolvimento democrático, traz ao debate alguns elementos-chave que exigem revista, a saber: representação, decisão, soberania e os próprios conceitos de político e esfera do direito. De pronto, deixo claro que não pretendo remontar diacronicamente estes conceitos, somente os trarei à discussão, como se verá a seguir, na medida em que se fizerem necessários à proposta deste trabalho.

Cabe salientar que, apesar da crítica que Carl Schmitt faz diretamente a atuação dos tribunais no controle da constitucionalidade (BERCOVICI, 2003, p. 196) - colocando este ator como inapropriado (se não incapaz) para o exercício de uma função que interfere diretamente na decisão política, visto que, para ele, somente o Presidente do Reich teria a autoridade e a legitimidade para tanto, pois o constitucionalismo estaria para além de um conjunto de normas que circunscrevem os limites da legalidade, o que por si só já castraria qualquer chance de levar adiante, nesses termos, um debate sobre o tema da judicialização -, é interessante olhar para alguns dos aspectos que este autor discute, e pensar o fenômeno em questão e sua expansão nos Estados democráticos de direito, em particular o brasileiro, através deles, visto que todos encontram-se imbricados.

Carl Schmitt, em sua crítica ao Estado liberal, nos conduz a reflexão sobre o processo de judicialização da política na medida em que traz em sua discussão questões que dizem respeito ao modus operandi do Estado em relação a esfera do político e do próprio direito; tal como salientado anteriormente, do direito compreendido como algo orgânico à comunidade política que dá sustentação à própria engenharia estatal. Nesse sentido, sabendo que o político possui autonomia em relação a qualquer outra dimensão da vida em sociedade e que em sua estrutura estão circunscritos todos os elementos e questões inerentes a ela, aquilo que irá determinar a preponderância de um aspecto (seja cultural, econômico, moral etc.) sobre o outro está justamente na capacidade que possuem de melhor se manifestarem através do conflito eminente, algo inerente a própria natureza do político; a qual se exprime, segundo Carl Schmitt, na díade amigo e inimigo. Acredito que pensar o político no contexto da judicialização da política se faz absolutamente pertinente, uma vez que é a partir desta compreensão que se fará possível notar os limites das incursões do próprio poder judiciário nos processos democráticos. O político em sua relação com Estado liberal, implica, segundo Schmitt, na pacificação das relações em prol da garantia de proteção aos direitos dos indivíduos; no cenário de intervenção do judiciário, o político permanece como uma esfera a ser controlada pelo Estado sob o aporte das leis. O pós-1988 no Brasil levou a 
expansão da arena do conflito político, uma vez que incorporou mais atores, contudo, nesse mesmo movimento o Estado permitiu com que se organizassem aparatos que lhe concediam o controle do político, mantendo sua atuação no âmbito da exceção respaldando-se por procedimentos/processos jurídicos. A decisão é legitimada através do próprio procedimento do sistema de direito, ao invés de se prestar às etapas do processo democrático e da política em seu caráter público (que se define no conflito eminente).

O direito, cabe reforçar, é, na chave Schmittiana, a expressão da relação harmônica estabelecida no Estado de direito, em que há a sensação, pela dominação da lei, de que a liberdade na lei e a temperança do legislador (último guardião do Direito) trarão garantias sobre a proteção da ordem existente, das liberdades individuais e contra tudo aquilo que for externo a esfera da legalidade. Nesse sentido, convém dizer que esta crença constitui o imaginário constitucionalista liberal que legitima parte das ações e decisões dos tribunais em diferentes países de tradição democrática, incluso o Brasil. Chaloub e Lima (2018) afirmam que no Brasil a figura do magistrado, do bacharel especificamente, é marcada por uma ideia de neutralidade e de idoneidade construída ao longo de uma tradição cultural que os via como aquele que detém o mais alto nível de conhecimento e o poder de decidir consciente das leis (do Direito). Isto, evidentemente, imbricado a concepção de um judiciário que vê na sua própria atuação a efetivação dos direitos fundamentais, marcou a Constituição de 1988 e o processo de redemocratização. Dessa maneira, com novos participantes na esfera pública e com a complexidade das relações entre eles, o judiciário, convencido de que há a necessidade de um poder que venha resguardar os direitos constitucionais em um cenário marcado pela pluralidade, incorporação e participação de novos atores, dedica-se à interpretação dos valores compartilhados por estes tendo em vista a sua efetivação, assumindo centralidade nos processos de decisão política (MACIEL; KOERNER, 2002). Vale ressaltar que essa configuração não se encontra em discrepância com a ideia de que o Estado de direito atua no espaço da exceção e se utiliza deste seja para a conservação de um status, seja para condução de uma mudança em algum sentido desejado.

A judicialização da política no Brasil está imersa num cenário em que a cultura jurídica, corroborada por um contexto social em que predominam um conjunto de relações políticoeconômicos que veem na figura do magistrado uma espécie de reeducador, marca o processo de redemocratização que teve como marco a Constituição de 1988. Os processos políticos, e também, os que dizem respeito a vida comum, movidos através de decisões judiciais, expõe a maneira como se operacionaliza o conflito (próprio da esfera do político), procedimentalmente. O procedimento jurídico tornou-se tanto um instrumento para efetivação e salvaguarda dos direitos fundamentados em Constituição, quanto um dispositivo de decisão política que os demais poderes lançam mão para 
modificar diretamente os resultados de questões que incidem diretamente sobre a organização social ou a própria engenharia estatal (WERNECK; BURGOS; SALLES, 2007; MACIEL; KOERNER, 2002). A democracia organizada em torno deste modus operandi nos conduz a outra expressão do direito (o direito como o estabelecimento de um poder e conjunto de elementos que se constituíram no conflito político), organizado ao longo desta jornada de estabelecimento de uma cultura democrática iniciada no momento de transição da estrutura política autoritária à nova república (NOBRE, 2013; SAFATLE, 2015). A esfera do político passa a ser conduzida pela terceirização da decisão do caso crítico, pela anti-animosidade. A representação creio que esteja em consonância ao formato em que se opera os limites dados a esfera do político. Cabe salientar que, até mesmo para Carl Schmitt, a representação se torna algo complicado quando é necessário tomar a decisão sobre o caso crítico (a seara incontornável do conflito político), momento em que se define o que estará estabelecido para o conjunto social, e o pluralismo, imbricado a isto, é melhor resolvido (chega ao ponto do consenso, da unidade política) pela representação do próprio Presidente do Reich (BERCOVICI, 2003). Entretanto, em um contexto no qual o judiciário assume algum protagonismo quanto às decisões políticas, os limites da representação são recolocados tal qual a engenharia política estatal opera e gesta o político.

Por fim, vale ressaltar que, dentro desse escopo, é a decisão, para Schmitt, que define quem é o soberano. A decisão sobre o caso excepcional (critico), que permite com que se verifique a qual autoridade é concedida o exercício do poder político.

Político é, em todo o caso, sempre o agrupamento que se orienta pelo caso crítico. Destarte, ele é sempre o agrupamento humano normativo e, por conseguinte, a unidade política sempre quando existe em absoluto, sendo a unidade normativa e "soberana" no sentido de que, por necessidade conceitual, a decisão sobre o caso normativo, mesmo quando este for um caso excepcional, sempre haverá de residir nela. (SCHMITT, 2008, p. 41).

Sabido, tal como Hirschl (2009) aponta, que os tribunais assumem a função de decidir sobre os casos críticos que incidem diretamente no arranjo político-cultural etc. (a megapolítica), e, em igual medida, há um modus operandi em torno dessa decisão que reordena a disposição dos atores na arena democrática, a decisão do político e de tudo o que é estabelecido a partir dessa esfera (incluso o próprio sistema de direito através do qual os tribunais operam) fica a cargo dos tribunais, e a vontade política, que mobiliza a mudança na própria engenharia estatal e no conjunto da sociedade, adquiri outros contornos. Resta-nos compreender qual é o novo delineamento da esfera do político e da vontade política que, imersos nesse modus operandi denominado judicialização da política, ainda se debate em meio a questões que só se definem os limites na medida em que determinam a extensão da dimensão desses elementos. 


\section{CONSIDERAÇÕES FINAIS:}

Este artigo representa o esforço de pensar, ainda que de maneira incipiente, caminhos que permitam levantar algumas discussões de pontos elementares que estão imbricados ao debate da judicialização da política, e de discuti-los a luz da crítica de Carl Schmitt sobre o Estado liberal e sobre o político. A judicialização da política, tal como foi apresentado, é um termo que vem ganhando robustez na medida em que as interferências do poder judiciário, realizadas principalmente através de suas decisões sobre questões centrais ou de grande impacto na vida política, tem, cada vez mais, o poder de determinar e de reordenar a composição de toda organização social e engenharia política estatal, seja de uma nação ou, até mesmo, de nações e de grupos humanos inteiros, como se vê nos casos de decisões via tribunais internacionais. No Brasil, o fenômeno teve um enorme impacto na vida política e sobre as relações sociais, e vem sendo, constantemente, foco de inúmeras controvérsias. Ele, como fora discutido, passou a ter maior notoriedade no pós-1988, quando houve a formalização das intenções em reconduzir a vida política nacional, e todas as relações imbricadas nela, à um processo de reconstrução da democracia, que havia sido maculada em todos os níveis, social, econômico, institucional etc., nos anos de ditadura.

Evidentemente que os debates, no Brasil, em torno do tema geraram, tanto a nível acadêmico, quanto a nível de opinião pública no geral, diferentes narrativas. Estas por sua vez se organizam em torno de preocupações que incidem diretamente sobre o modus operandi dos processos democráticos e da construção das relações entre os poderes circunscritos num desenho institucional que mescla modelos distintos de operacionalização das relações de forças políticas que emergem no contexto pós ditadura. Estudos e análises sobre o fenômeno, bem como a ação política engendrada pelos autores e atores envolvidos nesses processos, dividem-se em opiniões a favor e contra sua expansão sobre a vida política. Nesse sentido, procurei pensar estas problemáticas, concomitantemente às contribuições distendidas das reflexões de Carl Schmitt sobre o conceito do político, o Estado de direito e o liberalismo, principalmente, cogitando um caminho que permita alguma abertura para a apreensão do fenômeno da judicialização da política como parte de um modo de agir e de operacionalizar a esfera do político; englobando todas as relações sociais e de força, o sistema de direito, a vontade política, a engenharia política estatal e tudo aquilo que constitui o jogo democrático no qual organizamos nossas vidas.

\section{REFERÊNCIAS:}

BERCOVICI, Gilberto. 2003. Carl Schmitt, o Estado Total e o Guardião da Constituição. Revista Brasileira de Direito Constitucional (Comentários bibliográficos), no 1, jan./jun., pp. 195-201. 
CHALOUB, Jorge; LIMA, Pedro Luiz. 2018. Os juristas políticos e suas convicções: para uma anatomia do componente jurídico do golpe de 2016 no Brasil. Revista de Ciências Sociais.

Fortaleza, V. 49, No 1, Mar/Jun, pp. 202-252.

CASTRO, Marcus Faro. O supremo tribunal federal e a judicialização da política. In: Encontro Anual da Associação Nacional de Pós-Graduação e Pesquisa em Ciências Sociais - ANPOCS, 20, 1996, Minas Gerais. Anais do 20 Encontro Anual da Anpocs, de 22 a 26 de outubro de 1996, em Caxambu - MG. GT03 - Direitos, identidades e ordem pública.

DAHL, Robert. 1997. Capítulo 1. IN: Poliarquia: Participação e Oposição. São Paulo: Edusp.

FERREIRA, Bernardo. 2004. O risco do político: crítica ao liberalismo e teoria política no pensamento de Carl Schmitt. Belo Horizonte: Editora UFMG; Rio de Janeiro: IUPERJ.

HIRSCHL, RAN. O novo constitucionalismo e a judicialização da política pura no mundo. 2009. Revista de Direito Administrativo, n. 251, maio/agosto, pp. 139-178.

MACIEL, Débora Alves; KOERNER, Andrei. 2002. Sentidos da judicialização da política: duas análises. LUA NOVA, São Paulo, no 56, pp. 113-133.

NOBRE, Marcos. 2013. Desigualdades e pemedebismo na nova modernização brasileira. IN: Imobilismo em movimento: Da redemocratização ao governo Dilma. $1^{\mathrm{a}}$ ed. São Paulo: Companhia das Letras.

POGREBINSCHI, Thamy. 2012. Apresentação e Introdução. IN: Judicialização ou Representação?: política, direito e democracia no Brasil. Rio de Janeiro: Elsevier.

PRZEWORSKI, Adam. 1997. Una defensa de la concepción minimalista de la democracia. Revista mexicana de Sociología, pp. 3-36.

RODRIGUES, Paulo Joaquim da Silva. A judicialização e seus intérpretes: uma análise comparativa de referenciais teóricos. 2016. CONFLUÊNCIAS - Revista interdisciplinar de Sociologia e Direito. Vol. 19, No 2, pp. 145-169.

CARTA CAPITAL. SAFATLE, Vladimir. A Nova República acabou. Disponível em: $<$ https://www.cartacapital.com.br/revista/841/a-nova-republica-acabou-2242.html $>$ Último acesso em 21/07/2018.

SCHMITT, Carl. O conceito do Político/Teoria de Partisan. 2008. Belo Horizonte: Del Rey.

VIANNA, Luiz Wernerck; BURGOS, Marcelo Baumann; SALLES, Paula Martins. 2007.

Dezessete anos de judicialização da política. Tempo Social, revista de sociologia da USP, V. 19, n.2, pp. 39-85.

\footnotetext{
NOTAS:

${ }^{1}$ Em seu texto, O novo constitucionalismo e a judicialização da política pura no mundo (2009), Hirschl aponta três estágios do processo de judicialização da política que vem ocorrendo em diversos países do mundo no decorrer dos anos 1990 e ao longo dos primeiros anos da década de 2000. Segundo o autor há a emergência de uma terceira classe de judicialização da política (a megapolítica), e nela acontece ações que determinam o curso de toda uma coletividade.
} 
${ }^{2}$ Como se verá adiante, esse tema será retomado em diálogo direto com a tese de Carl Schmitt presente em $O$ conceito do Político. Logo, toma-se como "esfera do político" o próprio conflito constitutivo do conceito do político, que, tal como Schmitt (2008) aponta, é melhor compreendido a partir da díade amigo/inimigo.

${ }^{3}$ Hirschl (2009) levanta uma questão muito interessante para se pensar a diferença entre o que ele aponta ser o segundo e o terceiro níveis da política judicializada e, ainda que não discorra de forma analítica sobre, argumenta que para apreender as nuances desses tipos de incursos do poder judiciário na esfera política deve-se compreender o que é o "político". Isto nos dá margem, tal como será apresentado neste texto, a reflexões acerca do que vem a ser a esfera do "político" e a da "representação", e, também, a da decisão e do exercício do poder político (imbricado à ideia, lato senso, de soberania) que as acompanham.

${ }^{4}$ Dahl (2005), ao procurar compreender as condições que favorecem ou impedem a transformação de um regime político em que há uma oposição que não tem condições de se organizar abertamente ou que, simplesmente, não fora desenvolvido um sistema político que permita oposição e rivalidade entre governantes e seus oponentes, nos conduz a uma composição analítica em que duas dimensões se fazem essenciais para compreender o processo de democratização: o grau de liberdade de contestação pública e o de participação.

${ }^{5}$ Vianna, Burgos e Salles (2007), ao realizarem uma atualização das análises do estudo sobre judicialização da política publicado em 1999, Judicialização da Política e das relações sociais, que compreendia as Ações Diretas de Inconstitucionalidade (AdIns) entre os anos de 1988 e 1998, buscam verificar se os padrões de judicialização da política antes constatados ainda persistem, à época num cenário em que vigia uma forte coalisão à esquerda, e como variou, entre os anos de 1999 e 2005, o perfil dos autores e dos temas.

${ }^{6}$ Bercovici (2003) aponta que o Constitucionalismo para Carl Schmitt não representa um conjunto de leis nas quais está circunscrito o que é ou o que não é legal, mas ele é o próprio sistema de direito, carregado de tudo aquilo que dá forma a demos (ao povo) e aquilo relacionado a ela (Estado, Instituições, cultura, religião, economia, etc.). "A Constituição, portanto, vale em virtude da vontade política existente tomada pelo poder constituinte". (Bercovici 2003: 196).

7 Gisele Cittadino, segundo Maciel e Koerner (2002), parte da discussão das bases éticas e jurídico-normativas do constitucionalismo democrático, que prioriza os valores da dignidade humana e da solidariedade social, a ampliação da proteção dos direitos e mudanças nas relações entre os poderes do Estado, ao contrário do constitucionalismo liberal, que toma por base o individualismo racional, garantia limitado dos direitos civis e políticos e separação dos poderes. Isto, em consonância ao novo espaço público ocupado pelo judiciário, endossado pelo pensamento de que a efetivado dos direitos fundamentais se daria via as ações do círculo de intérpretes da esfera judicial construídas por meio de instrumentos processuais-procedimentais, não se apresentaria como um empasse ao desenvolvimento democrático, pelo contrário em harmonia com ele.

${ }^{8}$ Os pontos de vista sobre a questão foram fornecidos por: Dr. Sérgio Ferrari - Procurador da Câmara Municipal do Rio de Janeiro e Professor da UERJ -; Dr. Cláudio Brandão de Oliveira - Desembargador do Tribunal de Justiça do Estado do Rio de Janeiro -; Dr. Marlon Weichert - Procurador Regional da República e Procurador Federal dos Direitos do Cidadão Adjunto, no Seminário Políticas Públicas - Controvérsias Judiciais e o Espaço do Poder Legislativo, no Rio de Janeiro, em junho de 2018 .

\section{AUTORA:}

\section{Isabele Sales dos Anjos}

Mestre em Ciências Sociais pela PPCIS-UERJ. 